\title{
Design of a 100 MW Concentrated Solar Power Plant Parabolic Trough in Riyadh, Saudi Arabia
}

\author{
Huda Mohammed Alotaibi, ${ }^{1 *}$, Wael Al-Kouz ${ }^{1}$, Alberto Boretti ${ }^{1}$ \\ ${ }^{1}$ Mechanical Engineering Department, College of Engineering, Prince Mohammad Bin Fahd University, \\ Al-Khobar 31952, Saudi Arabia
}

\begin{abstract}
The increase in energy demand and the awareness of renewable energy has been raised due to environmental and climate change and the need to establish sustainable energy development. Using fossil fuels has created a critical situation such as; climate change, air pollution, and emission of greenhouse gases also, the resources are in limited supply. The infinite source of energy such as; the sun can provide an effective and sustainable energy supply. Riyadh city in Saudi Arabia is one of the areas that receive a high quantity of direct solar radiation. An average direct normal irradiance (DNI) for the central region is equal to 2018 $\mathrm{kWh} / \mathrm{m} 2 / y e a r$. This paper shows the design and the performance analysis of $100 \mathrm{MW}$ Concentrated Solar Power (CSP) parabolic trough (PT) power plants with thermal energy storage (TES) for use in Riyadh city. The performance of this design plant is analyzed by using the system advisor model (SAM). Based on the analysis carried out for this design, the capacity factor is equal to $45.3 \%$ with an annual energy generation which is equal to $396,801,792 \mathrm{kWh}$. By varying two main parameters, the solar field size and the full load hours of TES to get the optimal design of this plant is done. Based on the simulation result, the proposed design of $100 \mathrm{MW}$ parabolic trough at 1,150,000 m2 solar field size and $7 \mathrm{~h}$ TES gives the lowest Levelized Cost of Electricity (LCOE) with an assumed lifespan of the plant of 25 years.
\end{abstract}

\section{Introduction}

The energy consumption worldwide has been increased. World health organization, states that the consumption of energy in 2011 was about $2.5 \%$. The consumption of energy becomes even more in recent years which can increase the consumption of fossil fuel and environmental pollution [1]. However, environmental, climatic, and operative conditions, also the geographical locations, play a major role in the energy production of such systems $[2,3]$. The realization of the importance of using renewable energy has been raised due to climate change. The integration of the electrical grid with renewable energy is preferred by many countries around the world to save the environment and to have a sustainable energy supply [4]. The usage of solar energy such as; solar power would create new job opportunities, and provide access to energy to many people who don't have a proper energy supply today. Also, Solar energy has proved to be a beneficial source on the financial side besides the benefit to the environment [5]. Concentrated solar power (CSP) is one of the solar energy methods that absorbed the solar heat and then converted it to electricity. CSP has the advantage to store the energy and then convert it into electricity in the cloudy days or even after sunset unlike the photovoltaic (PV). Also, PV has disadvantages such as; the power output decreases as the cell temperature increases [6]. By using one MW of CSP can prevent 688 tons of $\mathrm{CO} 2$ as compared to a normal power plant [7]. One

*Corresponding author: Huda_m_alotaibi@ hotmail.com of the CSP methods is a parabolic trough which is simpler than the solar tower as well it has a better capacity factor [8]. The solar tower is another CSP method, but it needs more support and a large area for the structure and a large number of mirrors. Linear Fresnel which is also another CSP technology, this technology has disadvantages one of them, mirrors need to be spaced in a large area which means more cost, also this technology does not produce a very high temperature as compared to parabolic trough. One of the greatest advantages of using parabolic trough that the cost is low as compared to other technologies also produce a high temperature for a steam generation [9]. Using thermal energy storage (TES) in a parabolic trough technology helps to achieve a better capacity factor also solves the lack of production in the cloudy days and the night without the need to burn fossil fuel. Parabolic trough opposite to photovoltaic and solar tower which experience much cloud coverage [10]. There are many examples of solar thermal power around the world such as the solar thermal power station in Barstow, California which was completed in December 2014 with a Gross capacity of 280 MW. Solana Generating Station also a famous parabolic trough power plant in Arizona which was completed in October 2013, with 6 hours of TES and with an electrical capacity of $280 \mathrm{Mw}$ [11]. The national renewable energy laboratory NREL developed a parabolic trough spreadsheet and economic model that developed in an Excel program. NREL has many features such as; capital cost, the cost of the maintenance, and the financial 
calculation is added which makes the power plant design easier [12]. This paper is about simulating a model to build a parabolic trough in Saudi Arabia mainly in Riyadh.

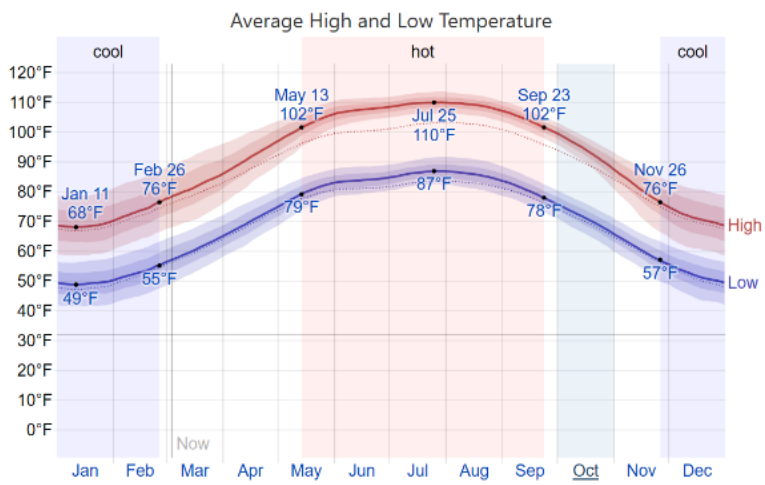

Fig. 1. The daily average high (red line) and low (blue line) temperature in Riyadh city. Image from [13].

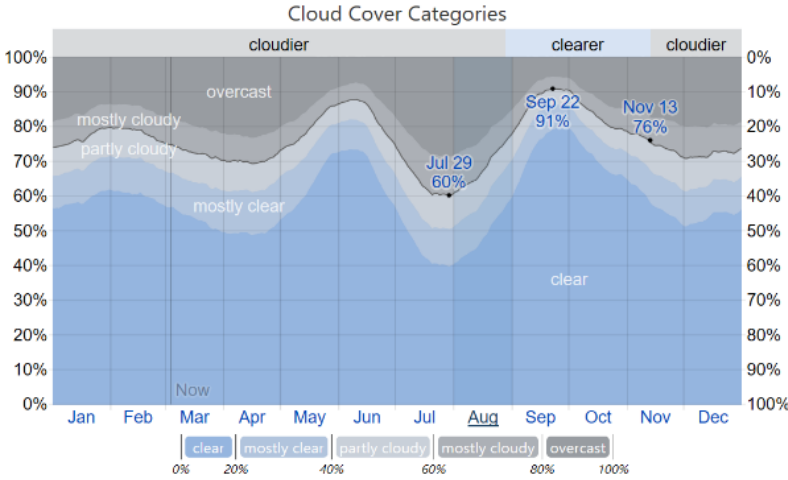

Fig. 2. Cloud Cover over the year in Riyadh city. Image from [13].

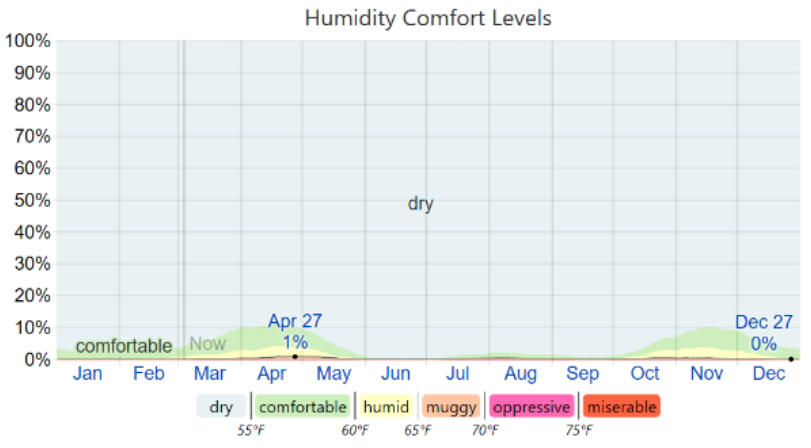

Fig. 3. Humidity level distribution over the year in Riyadh city. Image from [13].

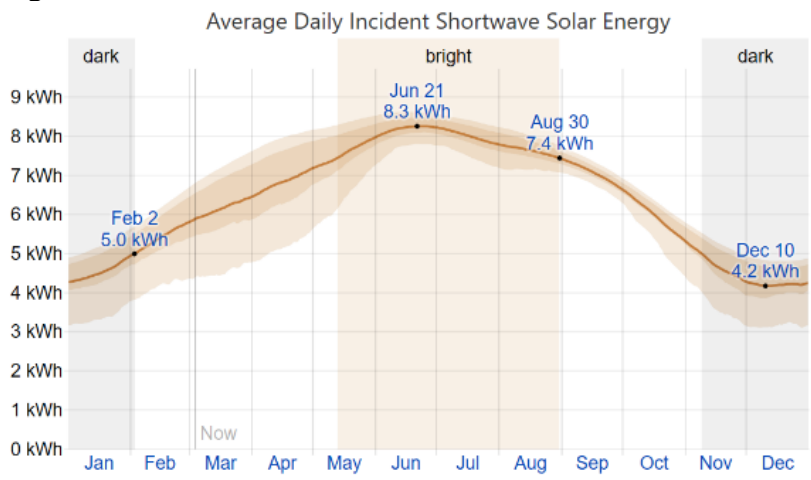

Fig. 4. The average shortwave solar energy over the year in Riyadh city. Image from [13].
Riyadh city is located $\left(24.7136^{\circ} \mathrm{N}, 46.6753^{\circ} \mathrm{E}\right)$. It is the capital city of Saudi Arabia. In Riyadh, the summer season is long, dry, and sweltering. In winter it is very cold and dry. The temperature in Riyadh varies from $\left(49^{\circ} \mathrm{F}\right.$ to $\left.110^{\circ} \mathrm{F}\right)$. Summer in Riyadh lasts for 4.3 months, which is from 13 of May to 23 of September. The highest temperature is recorded on the 25 of July which varies between $\left(110^{\circ} \mathrm{F}\right.$ to $\left.87^{\circ} \mathrm{F}\right)$. The cold season lasts for three months from 26 November to 26 of February, the highest temperature in these three months below $76^{\circ} \mathrm{F}$. On January 11 which is the coldest day in the winter season, the temperature varies between $49^{\circ} \mathrm{F}$ and $68^{\circ} \mathrm{F}$. On the 28 of August, the sky begins to be clearer and lasts for 2.5 months which ends on the 13 of November. The clearest day of the year is recorded on 22 of September, the sky is clear or $9 \%$ cloudy. The cloudier season in the year begins from November 13 and lasts for around 9.5 months, which ends on 28 August. On 29 July the sky is $60 \%$ cloudy. The rain falls within 31 days especially on 11 of March with an average accumulation of around 0.3 inches. The least rain falls on the 11 of July with an average accumulation of around 0.0 inches. The daylight length in Riyadh varies over the year. In 2020 the longest day is on 21 of June with 13 hours and $40 \mathrm{~min}$. The shorter day is on the 21 of December with 10 hours and $36 \mathrm{~min}$. On June 7 the sun rises at 5:03 AM which is the earliest day for the sun to rise and on the 14 of January, the sun rises at 6:39 AM. On November 29 the sunset at around 5:03 PM which is the earliest sunset and on the second of July the sunset is at 6:46 PM. The humidity in Riyadh remaining almost 0\%. The windier season is from May 22 to August 17 with an average speed equal to $8.7 \mathrm{mph}$. July 4 is known as the windiest day of the year with a wind speed of $10 \mathrm{mph}$. From 17 August to 22 May the weather is calmer which lasts for 9.1 months. October 8 is the calmest day with a wind speed of $7.4 \mathrm{mph}$. The direction of the wind mostly from the east, from (August 31 to October 9) which lasts for 1.3 months. The wind mostly from the north direction from May 21 to August 31 which lasts for 3.3 months. The wind mostly from the south direction from October 9 to May 19 which lasts for 7.3 months. The average incident solar energy undergoes seasonal variation over the year. The brighter season of the year lasts for 3.5 months from 12 May to August 30, with an average energy of $7.4 \mathrm{kWh}$. June 21 is known as the brightest day in the year with an average energy of $8.3 \mathrm{kWh}$. The darker season of the year lasts for 2.8 months from 9 November to February 2, with an average energy of $5 \mathrm{kWh}$. December 10 is known as the darkest day in the year with an average energy of 4.2 $\mathrm{kWh}$ [19]. The direct normal irradiance (DNI) for the central region equal to $2017.72 \mathrm{kWh} / \mathrm{m}^{2} /$ year [14].

\section{Materials and method}

SAM is developed by the National Renewable Energy Laboratory (NREL) computer model, which saves the effort to do the simulation of renewable energy. This section shows the details of the method used in developing SAM for 100 MW CSP parabolic trough that is located in Riyadh city. NREL developed a spreadsheet 
on the economic model and the performance of a parabolic trough in Microsoft Excel. One of the most important features of NREL is that capital cost, operation, and maintenance cost (O\&M), and financial calculation added directly to the model, which makes the plant design to be easier. This also allows us to have a detailed design project where the interaction between the cost and the performance can be accounted for. SAM is used by many people in the field of engineering, project management, and the technology development field. Based on the cost of installation and operation, SAM makes the prediction of performance and energy cost much easier. SAM needs weather data to show the weather condition and the renewable energy resource at the project location [15]. Using two tanks of molten salt as thermal storage especially at night can lead to great capacity factors. For each thermal storage size, a system developed for heat exchanger with log mean temperature differences (LMTD). The design of the heat exchanger and the solar field size can provide the energy with less cost for each size of TES [16]. Saudi Arabia has the highest exposed area. Geographically Saudi Arabia is located in a strategic location because; it has a widespread desert and is located in what is called the sunbelt. Saudi Arabia has average solar radiation between a minimum of $4.479 \mathrm{kWh} / \mathrm{m} 2 /$ day which is in Tabuk and a maximum of $7.004 \mathrm{kWh} / \mathrm{m} 2 /$ day which is in Bisha. For Riyadh, it is equal to 5.528 $\mathrm{kWh} / \mathrm{m} 2 /$ day. CSP power plant can be installed only where the DNI $>5.5 \mathrm{kWh} / \mathrm{m} 2 /$ day. The solar field is the most significant deciding parameter for the design of the CSP plant [15]. Parabolic trough plant contains the following subsystem; power cycle, solar collector, receiver with HTF system and back up fossil-fired (optional). The power plant of a parabolic trough works on a cycle, the fluid absorbed the heat then transfer it to the water through a heat exchanger to be hot enough to generate the steam. The schematic of the Parabolic Trough Power plant as seen in Figure 5. In a parabolic trough system, the sun is concentrating on a parabolic shape collector which is then reflected towards the receiver pipe. The temperature of the heat transfer fluid increased then, this heat transfer to the power cycle through a heat exchanger to generate electricity in the steam generator, the steam is then cooled, condensed, and reused. This heat transfer fluid can also heat the thermal storage system which can generate electricity when the sun is not shining [17]. There are many parameters to be specified in this paper such as; the solar field size and the full load TES. The first CSP factor is the solar field which is the area where the solar collector is installed. The solar field which consists of one or even more loops of solar collector assemblies (SCA's) can be expressed as a solar field apparatus or as solar multiple. Each SCA is expressed as an independent node calculation, the temperature across each node is represented in eq. [2.1] [18]. The receiver (HCEs) that is used for the power plant is Schott PTR80 which was selected from the SAM receiver library. This receiver has an inner diameter of $0.076 \mathrm{~m}$, with an outer diameter of $0.12 \mathrm{~m}$ for the glass envelope, at annulus pressure of 0.0001Torr. Therminol VP-1 is the HTF that is heated up and circulated through the receiver inner diameter that is used as the source for the plant cycle with $12 \mathrm{C}^{0}$ and $400 \mathrm{C}^{0}$ as a minimum and maximum HTF operating Temperature. Therminol VP-1 is a suitable option due to its lower viscosity, higher specific heat, and density for uniform, dependable, and efficient performance [18]. The collector is defined as the part of the solar field that reflects the sunlight to the receiver as seen in figure 6 . The collector that is selected in SAM is Sky Fuel SkyTrough (with 80-mm OD receiver), with $656 \mathrm{~m} 2$ for the apparatus area and $6 \mathrm{~m}$ width. The length of the collector is $115 \mathrm{~m}$, the piping distance is $1 \mathrm{~m}$. Tracking error which means the inability of the collector to orient perfectly along the tracking angle is equal to 0.988 . The power block has a conversion efficiency of 0.356 , an inlet temperature of $391^{\circ} \mathrm{C}$, and an outlet temperature of $293^{\circ} \mathrm{C}$. The thermal storage HTF fluid name is (Hitec Solar Salt), which is cheaper than thermal oil with a minimum operating temperature of $238{ }^{\circ} \mathrm{C}$ and a maximum operating temperature of $593{ }^{\circ} \mathrm{C}$. Any further equations are defined in [18]. By varying the full load hours TES, the amount of energy will be change as well as the cost of the energy. The financial model that is used in this paper is the Levelized Cost of Electricity (LCOE). To get the best parabolic trough design; one method is by doing different trials based on varying the solar field size and TES to get the lowest LCOE. This means as the LCOE is lower as the total capital cost and the operating cost are low and the annual electricity production is high, for further analysis about parabolic trough cost see [19].

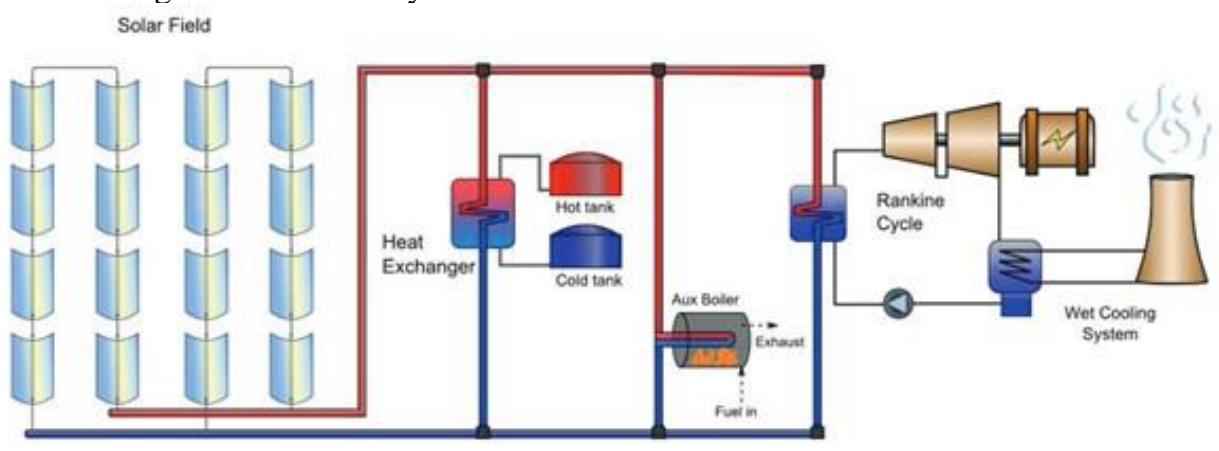

Fig. 5. Parabolic trough power plant scheme from [17]. While this case refers to a wet cooling system, in our case we use a dry condenser. 


\section{Result}

Figure 6 showed the data of thermal power incident (red color), cycle thermal power input (orange color), and net electrical output (blue color) for the solar plant in Riyadh. The net electrical output depends on the incident irradiation and the input thermal power depends on the
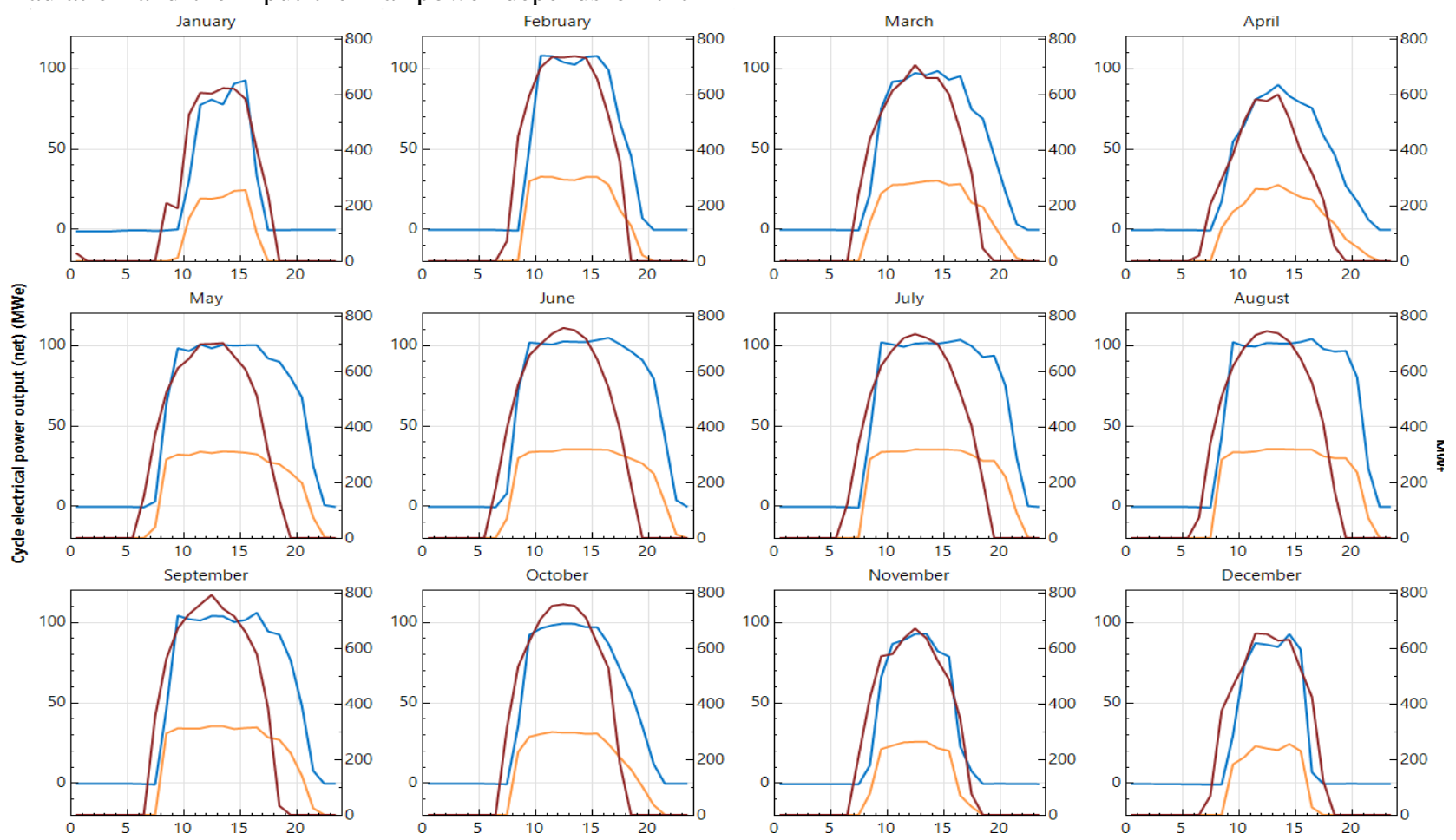
power is found around $300 \mathrm{Mw}$ in August, this is because August and June are the hottest months and there is more solar radiation. The cycle efficiency of a solar plant in Riyadh showed that the maximum cycle efficiency is found around 0.36 in June.
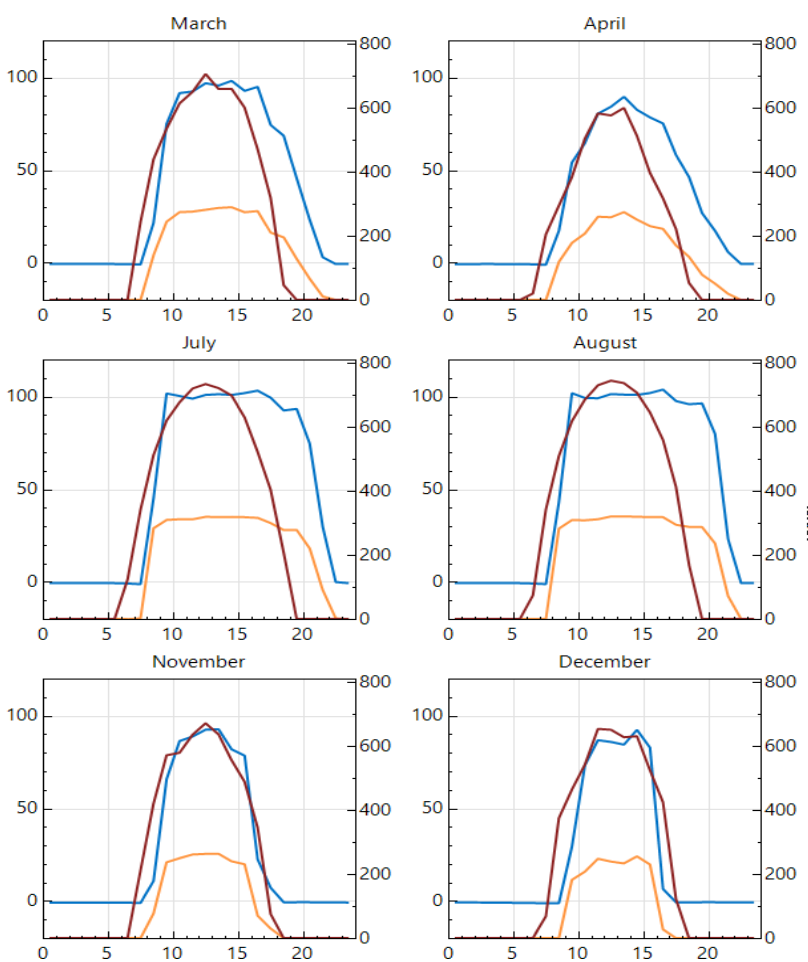

Fig. 6. Data of the thermal power incident (red color), cycle thermal power input (orange color), and net electrical output (blue color) for the solar plant in Riyadh city.
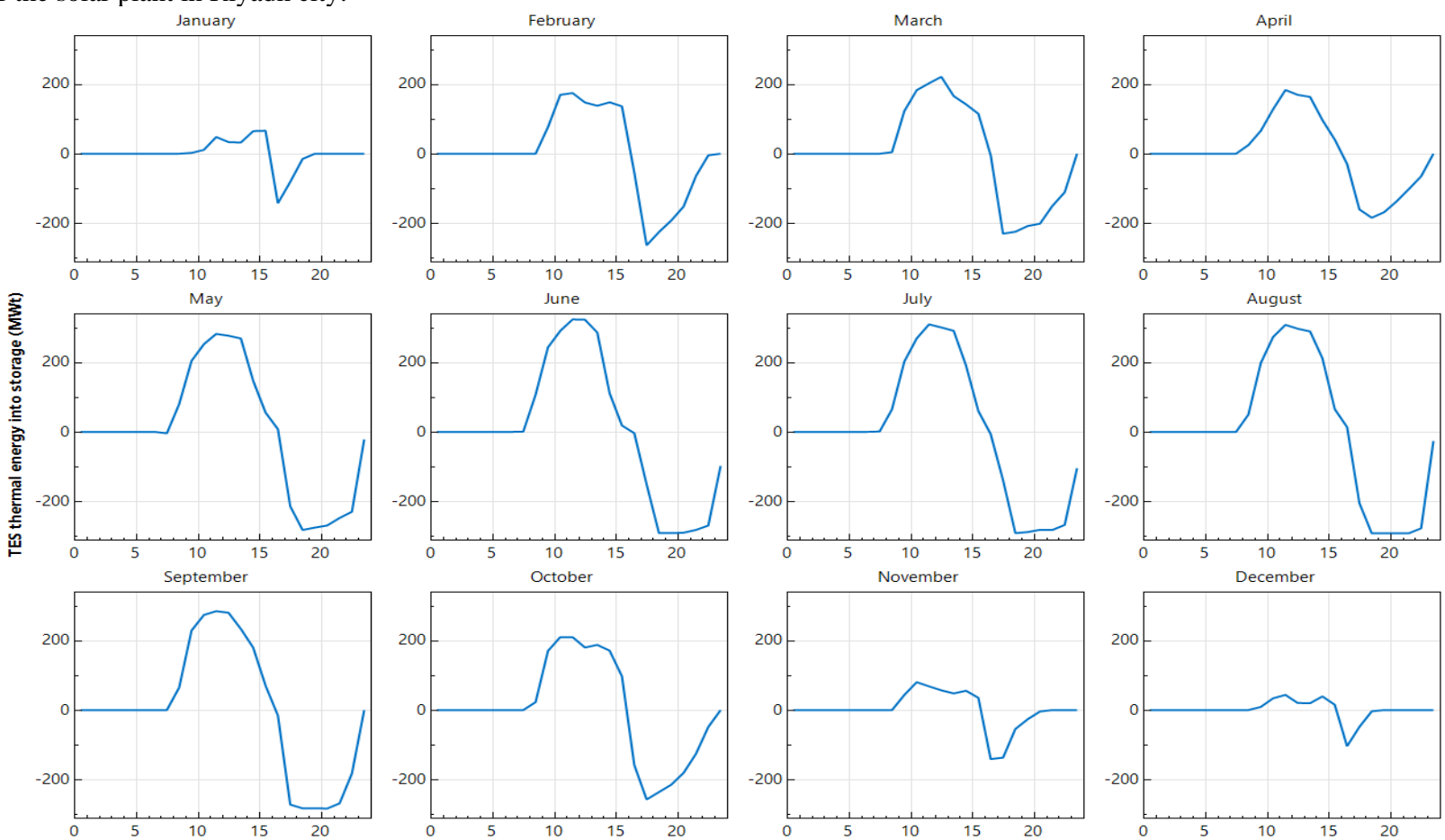

Fig. 7. Time rate of change of energy in the storage (MWt)

Thermal energy into storage as seen in figure (7), showed that in the hot season especially from June to August due to the high sun radiation there is more energy
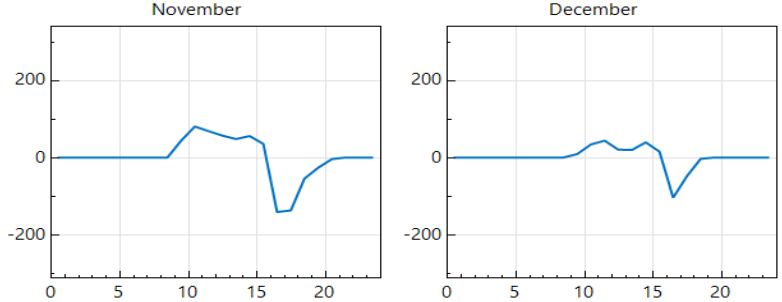

storage in the molten salt tank as well the usage of this energy reaches its maximum in these months. Dry bulb temperature is the temperature of ambient air, in the hot 
months such as July and August, it reaches the maximum temperature which equals $42^{\circ} \mathrm{C}$ at noontime. By using the system advisor model (Sam) and after specifying the location and resource of Riyadh city, the second step is to change some parameters to get the optimum design. In this paper, the change is based on the solar field size $\left(\mathrm{m}^{2}\right)$ and to see the effect of this change in different important parameters such as capacity factor, the net capital cost, and the LCOE, and then the change will be based on the full load TES. Figure (8), shows how increasing the solar field size will affect the capacity factor. It is found that as the solar field size increases as the capacity factor increase too, this is because as we increase the size of the solar field more solar radiation will be captured and this will increase the capacity factor which is the ratio between the actual energy output to the maximum possible energy output. In terms of the net capital cost from Figure (9) it is found that as the solar field size increases as the cost increases too, this is because as the solar field increases in size more cost will be for more equipment and maintenance as well. In the case of the LCOE, there is no direct relationship with the solar field size. To get the best parabolic trough design one method is by doing different trials based on varying the solar field size to get the lowest LCOE as seen in figure (10).

TES method to retain thermal energy, so the heat can be converted into steam and then generate electricity at night or in bad weather where there is no enough sunlight. Then the simulation was done based on the TES at a solar field size of $1,150,000 \mathrm{~m}^{2}$. It's found that as there are more TES as the capacity factor increases because the actual electrical energy output increases too. The capital cost also increases as the TES increases because more storage equipment is needed.

After getting all the values needed with different solar field size, figure $(8,9,10)$, showed the relationship between the solar field size and the capacity factor, the net capital cost, and the LCOE. there is a direct relationship between the solar field size with the capital cost and the capacity factor. It observed that the LCOE reaches its minimum value which equals $11.84 \$ / \mathrm{kWh}$ at the solar field size of $1,150,000 \mathrm{~m}^{2}$. If the solar filed size increase beyond this value the LCOE will increase again as seen in figure (10). With a capacity factor of $43.90 \%$ and the capital cost equal $\$ 688,114,816$. The design was conducted with a $6 \mathrm{~h}$ full load of TES. To see the effect of TES in a specific solar field size of $1,150,000 \mathrm{~m}^{2}$ based on the LCOE as seen in figure (11), that the lowest LCOE value was obtained at $7 \mathrm{~h}$ of TES with a capacity factor of $45.30 \%$ and the capital cost equal $\$ 714,215,232$. This plant generates the energy of $396,801,792 \mathrm{kWh}$ yearly. This result showed a greet agreement with a previous simulation that was done in Riyadh city [20]. The cash flow as seen in figure (12) the equity of $\$ 331,731,616$ can be recouped within the life of the solar system ( 25 years), in year 1 the payback almost $70 \%$ which is a good thing to be considered.

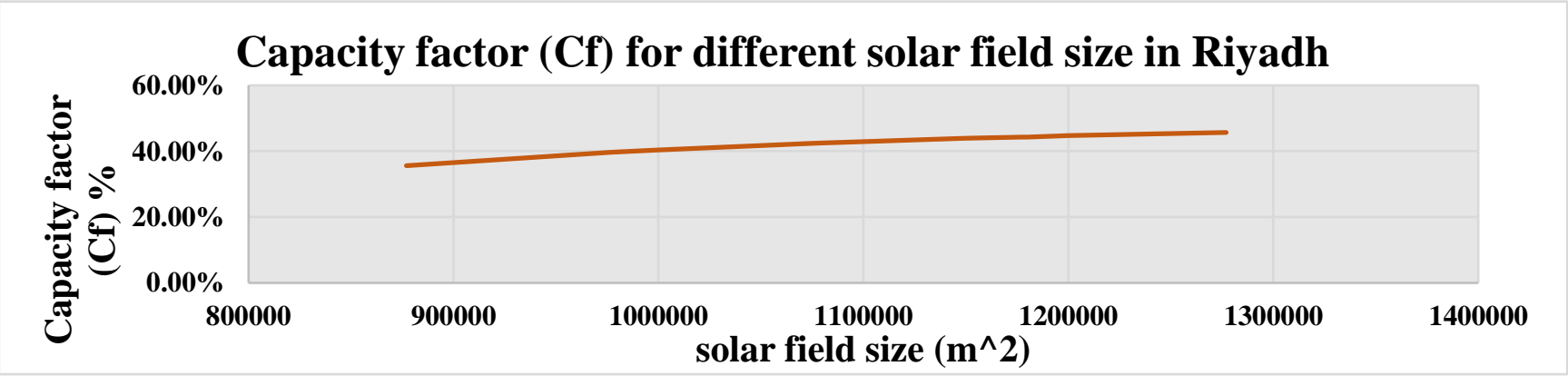

Fig. 8. Relationship between the capacity factor and the solar field size.

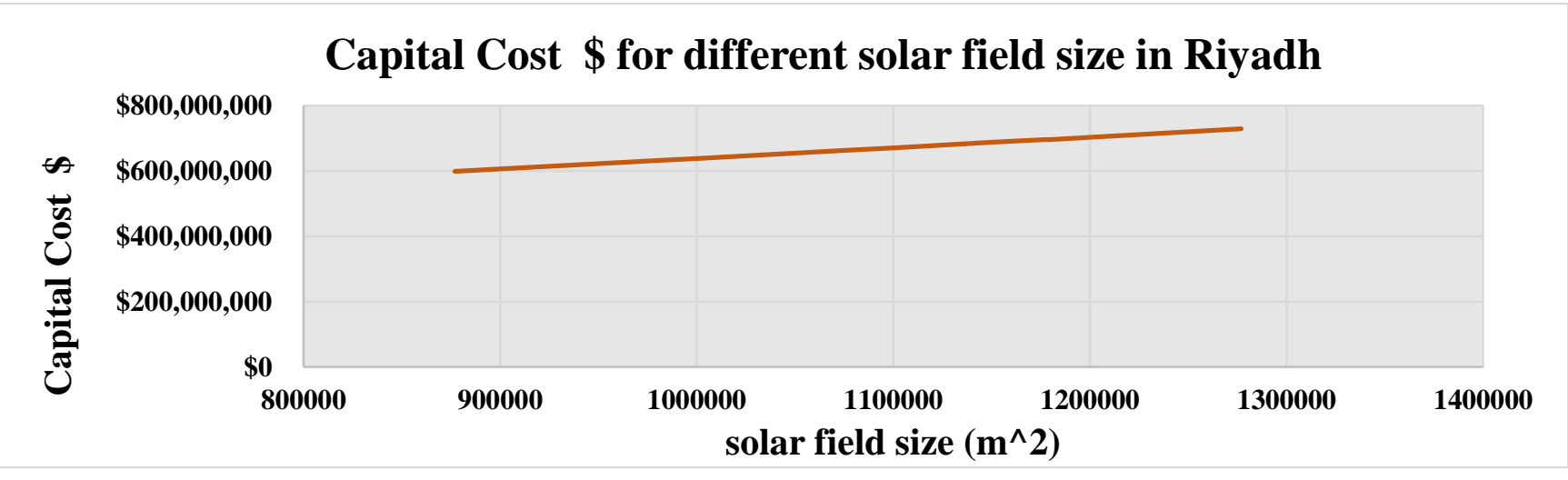

Fig. 9. Relationship between capital cost and the solar field size. 


\section{LCOE for different solar field size in Riyadh}

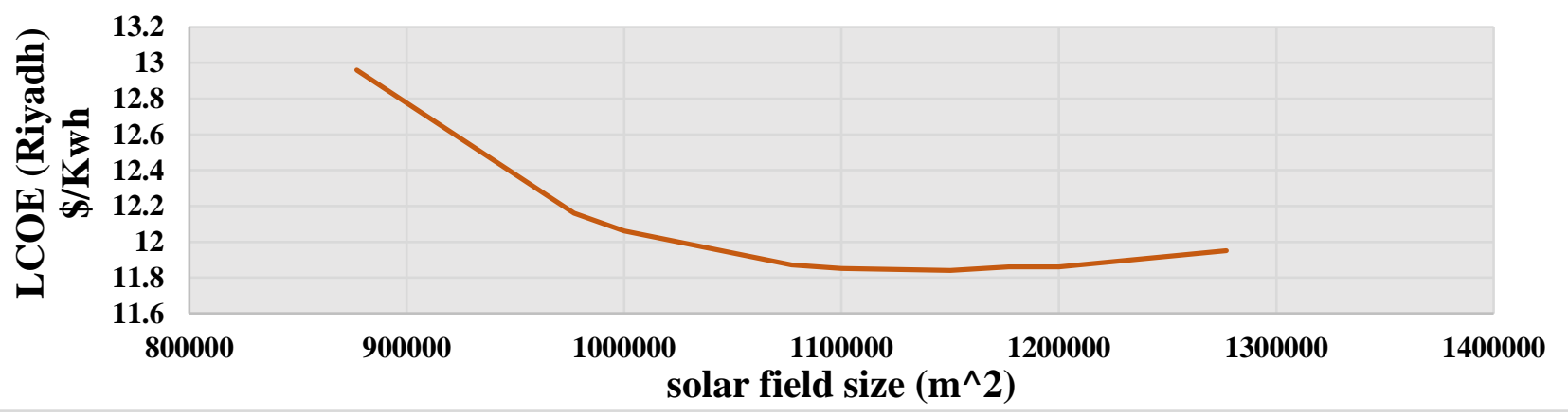

Fig. 10. Relationship between the LCOE and the solar field size.

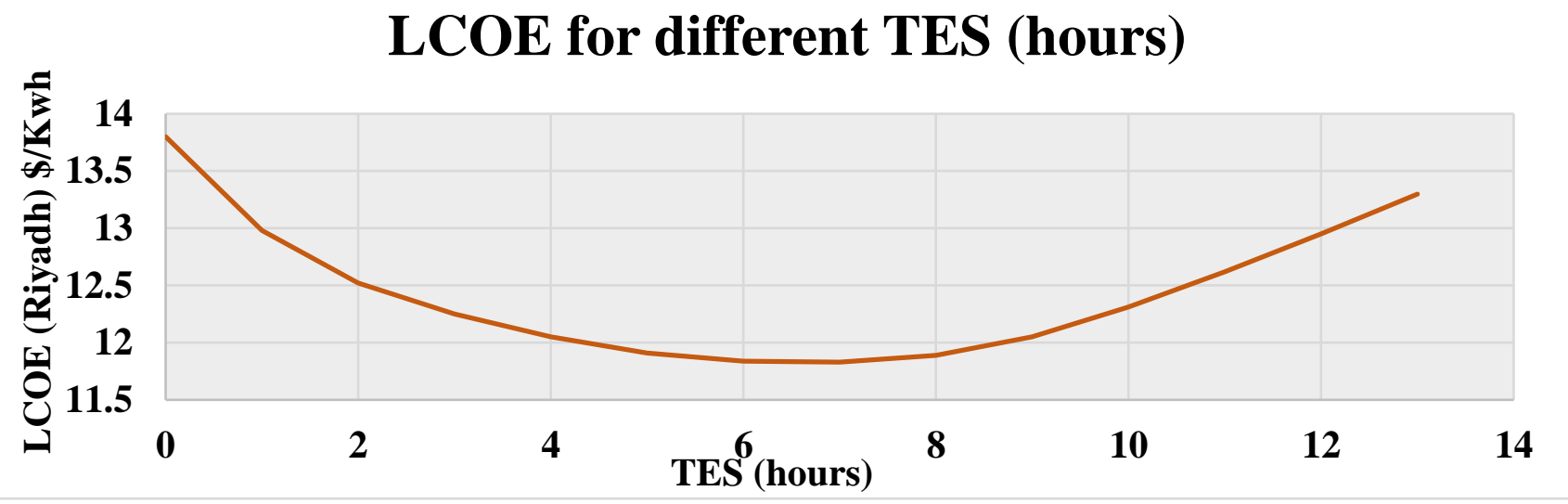

Fig. 11. Relationship between the LCOE and the TES.

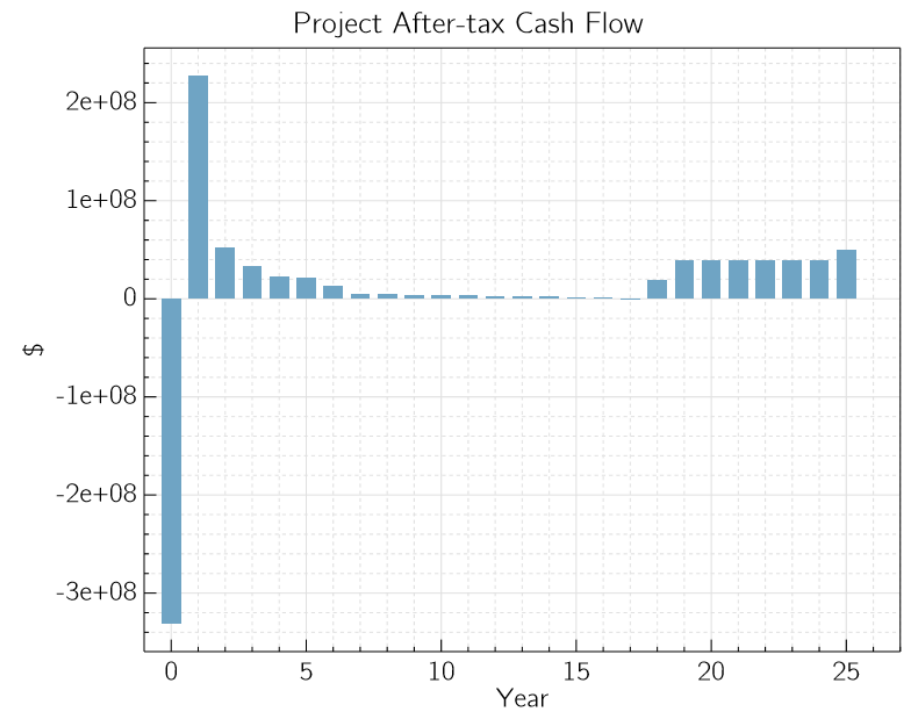

Fig. 12. Shows the long-term financial profile over the 25 years analysis. Positive values of cash flow represent an influx of money while negative values correspond to outgoing payments.

\section{Discussion and conclusion}

NREL develops an important tool that provides an integration of a parabolic trough model design with the plant performance, economic analysis, and the system capital cost. This helps the researchers to optimize the plant design with less effort and time. Based on the CSP power plant criteria located in Riyadh city, a simulation of $100 \mathrm{MW}$ parabolic trough solar power with thermal energy storage is done by SAM software. The DNI for the central region equal to $2017.72 \mathrm{~kW} / \mathrm{m} 2$. The performance of the CSP plant is optimized by varying some parameters such as solar filed size and the full load hours of TES. The 
optimum values for solar field size and full load hours of TES for Riyadh are found to be $1,150,000 \mathrm{~m} 2$ and $7 \mathrm{~h}$ respectively. This configuration leads to a decrease in LCOE value which equals $11.83 \$ / \mathrm{kWh}$ and increases the capacity factor to $45.30 \%$ and the annual electricity production by using Therminol VP-1 as HTF. This plant generates the energy of $396,801,792 \mathrm{kWh}$ yearly and the capital cost equals $\$ 714,215,232$. This design is done without considering dust and sand effects which cannot be done by SAM. Based on this findings TES system of a 100 MW parabolic trough Solar Power can be ideally suited in the central region of Saudi Arabia which can contribute to the future of sustainable energy in this region.

This activity has been performed as a supervised activity during the course of Advanced Heath Transfer. All the authors contributed to the final version of the manuscript.

\section{References}

1. Guzman, L., A. Henao, and R. Vasquez. "Simulation and optimization of a parabolic trough solar power plant in the city of Barranquilla by using system advisor model (SAM)." Energy Procedia 57 (2014): 497-506.

2. Al-Kouz, Wael, et al. "Modeling and analysis framework for investigating the impact of dust and temperature on PV systems' performance and optimum cleaning frequency." Applied Sciences 9.7 (2019): 1397.

3. Almuhtady, Ahmad, et al. "Investigation of the trends of electricity demands in Jordan and its susceptibility to the ambient air temperature towards sustainable electricity generation." Energy, Sustainability and Society 9.1 (2019): 1-18.

4. Kassem, Abdulrahman, Kamal Al-Haddad, and Dragan Komljenovic. "Concentrated solar thermal power in Saudi Arabia: Definition and simulation of alternative scenarios." Renewable and Sustainable Energy Reviews 80 (2017): 75-91.

5. Nader, Nader, Wael Al-Kouz, and Sameer Al-Dahidi. "Assessment of Existing Photovoltaic System with Cooling and Cleaning System: Case Study at AlKhobar City." Processes 8.1 (2020): 9

6. Al-Bashir, Adnan, et al. "Analysis of Effects of Solar Irradiance, Cell Temperature and Wind Speed on Photovoltaic Systems Performance." International Journal of Energy Economics and Policy 10.1 (2020): 353.

7. Răboacă, Maria Simona, et al. "Concentrating solar power technologies." Energies 12.6 (2019): 1048.

8. Boretti. Albert "Concentrated Solar Power Plants Capacity Factors: A Review". Nonlinear Approaches, In Engineering Applications Energy: Vibrations, And Modern Applications, Liming Dai, Eds., Reza N. Jazar, Springer, New York. Dx.Doi.Org/10.1007/978-3-319-69480-1_2, 2018.

9. Islam, Md Tasbirul, et al. "A comprehensive review of state-of-the-art concentrating solar power (CSP) technologies: Current status and research trends." Renewable and Sustainable Energy Reviews 91 (2018): 987-1018.

10. Adib, Rana, et al. "Renewables 2015 global status report." REN21 Secretariat, Paris, France (2015).

11. Price, Henry W. Parabolic trough solar power for competitive US markets. No. NREL/CP-550-25798. National Renewable Energy Laboratory, Golden, CO, 1998.

12. Bonilla, Javier, et al. "Parabolic-trough solar thermal power plant simulation scheme, multi-objective genetic algorithm calibration and validation." Solar Energy 86.1 (2012): 531-540.

13. Average Weather in Riyadh, Saudi Arabia, Year Round - Weather Spark. (2020). Retrieved 11 September 2020, from https://weatherspark.com/y/104018/AverageWeather-in-Riyadh-Saudi-Arabia-Year-Round

14. Daily Average of Direct Normal Irradiance (DNI) in 2018. (2020). Retrieved 10 March 2020, from https://www.stats.gov.sa/en/indicators/227

15. Bishoyi, Deepak, and K. Sudhakar. "Modeling and performance simulation of 100 MW PTC based solar thermal power plant in Udaipur India." Case studies in thermal engineering 10 (2017): 216-226.

16. Price, Henry. "A parabolic trough solar power plant simulation model." International solar energy conference. Vol. 36762. 2003.

17. Liaqat, K., et al. "Modeling and Simulation of a 100 MW Concentrated Solar Thermal Power Plant Using Parabolic Trough Collectors in Pakistan." MS\&E 414.1 (2018): 012032.

18. Wagner, Michael J., and Paul Gilman. Technical manual for the SAM physical trough model. No. NREL/TP-5500-51825. National Renewable Energy Lab. (NREL), Golden, CO (United States), 2011.

19. Kurup, Parthiv, et al. "Parabolic Trough Collector Cost Update for the System Advisor Model (SAM) Parabolic Trough Collector Cost Update for the System Advisor Model (SAM)." (2015).

20. Kassem, Abdulrahman, Kamal Al-Haddad, and Dragan Komljenovic. "Concentrated solar thermal power in Saudi Arabia: Definition and simulation of alternative scenarios." Renewable and Sustainable Energy Reviews 80 (2017): 75-91. 